\title{
Effects of nightlife activities on urban spaces and design: a case study of Cairo, Egypt
}

\author{
Abeer Elshater ${ }^{1 *}$ (I) and Hisham Abusaada ${ }^{2}$
}

\begin{abstract}
Hyper-diversity in old communities should be rehabilitated to address various man-made changes that threaten sustainability and viability at night. This study elucidates this argument by reviewing and synthesising theoretical and empirical evidence about urban governance support regarding the participation of neighbourhood residents to improve or eliminate nightlife. The method is based on a systematic review, direct observation and interview with random samples of residents, workers and visitors in commercial and recreational places. This study criticises changes in the public space of the Al-Hussein Mosque, which led to changes in urban forms and affected the nightlife in Old Cairo. However, it asserts that the hyper-diversity of activities in public spaces because of the lack of urban governance controls should consider changes in terms of the participation of vulnerable groups in nightlife. A new conceptual framework for interpreting stakeholders' positive and negative responses is proposed, which operates across four overlapping steps of urban governance: predicting, proposing, preparing and preventing.
\end{abstract}

Keywords: Hyper-diversity, Participation, Old Cairo, Vulnerable groups, Urban governance

\section{Introduction}

Over the past two decades, there has been considerable research on the diversity of urban environment characteristics and its influence on urban form and daily life (Alipour \& Ahmed, 2021; Nguyen, 2018; Sharifi, 2019). Some studies investigated the impact of the diversity of these characteristics on nightlife patterns (Kalinauskaite et al., 2018; Nofre et al., 2017; Hadfield, 2015), focusing on night regulations and the need for permanent structures for night governance that challenge traditional urban management methods (Seijas \& Gelders, 2021). Moreover, the appeals to examine the reasons for the changing urban nightlife associated with urban transformation in several public spaces in old communities with a historical dimension have been increasing (Kalinauskaite et al., 2018; Peterson, 2016; van Liempt et al., 2014).

The literature on urban studies has discussed the effects of diversity of activities in public spaces, specifically

\footnotetext{
*Correspondence: abeer.elshater@eng.asu.edu.eg

${ }^{1}$ Department of Urban Design and Planning, Ain Shams University, Cairo, Egypt

Full list of author information is available at the end of the article
}

focusing on the hyper-diversity of such activities (TasanKok et al., 2014). Furthermore, several theorists have discussed diversity and hyper-diversity from the perspective of spatial diversity in normal diurnal time as per mixed use to achieve place vitality and social cohesion (Ahmadi, 2018; Ballet et al., 2020). In turn, hyper-diversity supports a sense of intimacy and stimulates a sense of belonging (Tasan-Kok et al., 2014). However, a significant part of academic work and applied research within urban planning and design that discuss issues related to urban form and daily experience (McClinchey, 2017) primarily focuses on daytime activities (Kalinauskaite et al., 2018). The literature on social sciences and urban studies has discussed the theory of hyper-diversity in relation to lifestyle (Dean et al., 2018; Peterson, 2016). This theory goes beyond ethnicity and socio-economic differences; it covers the complex relationships between the variables that occur in the urban environment because of the diversity present in each situation (Kraftl et al., 2019).

Regarding the exanimation of nightlife activities, few studies have highlighted issues related to night-time planning (Seijas \& Gelders, 2021), many of which focused 
on issues such as urban entertainment (Campo \& Ryan, 2008), night-time city (Roberts \& Eldridge, 2019), nightlife atmosphere (Kalinauskaite et al., 2018), urban change (Nofre et al., 2017) and artificial lighting (Talebian \& Riza, 2020). Meanwhile, the discussion on social sustainability dimensions, especially the sustainability of the community in terms of social inclusion and sense of belonging (Kohon, 2018), is scarce (Alipour \& Ahmed, 2021; Ballet et al., 2020). Moreover, sense of belonging because of urban nightlife and form changes require further examination (Abussada et al., 2021).

The literature has described sense of belonging and its importance to citizens, as well as how its loss can lead to problems (Pinkster, 2016; Yuval-Davis, 2006), such as the lack of place (Russo, 2021) and the willingness of vulnerable groups to care for a place as if they owned it (Elshater 2019). People who initially lost their sense of belonging refuse to participate in city development and become provocateurs of spatial violations in terms of the elements of urban form and daily life (Nofre et al., 2017). These violations frequently appear in two aspects: visual pollutants and behavioural reactions (Chmielewski et al., 2016; Portella, 2014). A recent systematic review found that an individual's sense of belonging diminishes when one loses the ability to participate in critical decisions about where to live; recent studies have examined this problem (Peterson, 2016; Pinkster, 2016). This problem also is observed when people reject urban changes and are unable to participate in required discussions, even if such changes are relevant to them. Because of these factors, issue emerges that this feeling of neglect can lead to frustration and loss of sense of place (Elshater, 2019). Generally, this feeling generates negative behaviours towards the place or even failure to repel attacks on the place (Dastgerdi, \& Luca, 2019).

In this manner, an individual becomes a spectator from afar and does not offer interference. Therefore, the absence or non-implementation of urban governance and decision-making systems in order to encourage vulnerable and disadvantaged groups, such as residents and expatriate workers, to participate in developing their areas with their local governments is an aspect that may lead to urban nightlife deterioration. Thus, sense of belonging due to changes in urban nightlife, urban form and urban governance should be investigated.

Studies that focus on night-time planning (van Liempt et al., 2014) and the governance of the night-time city and night-time activities are few (Hadfield, 2015; Roberts \& Eldridge, 2019; Seijas \& Gelders, 2021). Such studies have investigated the socio-physical context, behaviour and experiences revealed from activities in public spaces that are very apparent, such as meeting others (van Liempt et al., 2014, p. 418). Moreover, some studies have examined the urban nightlife atmosphere (Kalinauskaite et al., 2018). However, urban studies in general and Egyptian studies in particular lack a conceptual framework and tools for creating harmony between residents and local entity participation in terms of urban control in old cities with a historical character. This issue requires reviewing the concept of belonging and the reasons for the loss of the sense of belonging from three perspectives: (1) the increased diversity of nightlife activities in public spaces and their influence on the uniqueness of the place and its historical value, (2) overlooked participation of vulnerable groups in development projects and their loss of responsibility and (3) the absence of urban governance and decision-making systems that limit changes in the characteristics of the place, especially those that stipulate the importance of the participation of vulnerable groups in developing their local communities.

The study addresses the absence or non-implementation of urban governance and decision-making systems to promote the participation of vulnerable and disadvantaged groups, specifically residents and expatriate workers, in developing their communities with local governments. Ignoring this problem may deteriorate urban nightlife.

This study's objectives are related to the nightlife characteristics of ancient cities. The first objective is investigating the impact of over-diversified changes in the activities of public places during night time in an Egyptian historical context, which is recognised on the facades of buildings and constructed features of public places. This study focuses on the facades and adjacent outdoor spaces of new and historical buildings with uses and functions on the ground floor (Dean et al., 2018; Kraftl et al., 2019). The second objective is setting up a framework that can foster societal justice and its association with decision-making and participation. In terms of the research problem, this study selects the case of Al-Hussein in Cairo, Egypt, which is an old community that has a historical dimension. The study intends to demonstrate that the hyper-diversity of activities in public spaces is a predictor of changes in urban form as a spatial domain and in nightlife as a time domain. Additionally, this study emphasises the impact of vulnerable groups' nonparticipation in development projects on nightlife. This change occurs through the agreement to, or prevention of, changes initiated by local governments, visitors or labourers (Nofre et al., 2017). The study also focuses on the extent of the link between these changes and sense of belonging. This study could be beneficial to the relevant communities, policymakers and/or urban planners as it investigates the potential advantages of the hyperdiversity of nightlife activities in public spaces and their transformation during the night. Further, it is hoped that 
developing a conceptual framework and a tool will enable policymakers to improve the nightlife atmosphere.

\section{Data collection and processing}

The study focuses on the effects of hyper-diversity of nightlife activities in public spaces, which may occur among vulnerable and non-affiliated users. Such an effect may also negatively affect the nightlife ambiance in old communities in Cairo. This study used two approachesnamely, systematic review and observation/interviewto investigate hyper-diversity in historical sites, such as Al-Hussein.

\section{Data mining in literature}

The systematic review identified six topic clusters. Scimago Journal \& Country Rank, powered by Scopus, was used for identifying studies related to this topic. An in-depth scoping review was conducted on 26 randomlyselected articles from 18 journals between 2014 and 2021 (Fig. 1). This review identified coexisting words in article titles, abstracts and keywords (see Additional file 1 and Fig. 2).

These words included [TITLE-ABS-KEY (social AND sustainability) OR TITLE-ABS-KEY (resilience) AND TITLE-ABS-KEY (nightlife) OR TITLE-ABS-KEY (urban AND from) OR TITLE-ABS-KEY (everyday AND lifestyle) OR TITLE-ABS-KEY (principles) OR TITLE-ABS-KEY (old AND cities) OR TITLE-ABSKEY (guidance AND for AND practitioners)].
The results yielded 13,647 documents. The authors limited the selection by randomly picking articles published by authors with a Scopus $h$-index higher than six and only including articles written in English. Books, book chapters and conference proceedings were excluded from the list. The aim of scanning the results was to determine whether the hyper-diversity of nightlife activities in public spaces improve or threaten nightlife. Data mining intends to investigate the effect of the absence of vulnerable and non-affiliated groups in decision-making on the hyper-diversity and threat of nightlife.

\section{Case study setting}

Old Cairo (969 AD) in Egypt is an ancient city (Hassan et al., 2016); it features multiple historical monuments, such as the Al-Azhar Mosque (972 AD), Al-Hussein Mosque (1154), Khan Al-Khalili Bazaar (1882) and numerous historical buildings (O'Kane, 2016). In the Al-Gamaleya District in Old Cairo, the public space of the Al-Hussein Mosque is one of the most well-known historical sites in Egypt (Fig. 3). The mosque establishment date is in 1873 (O'Kane, 2016).

Old Cairo is characterised as a mixed residential, commercial, religious and entertainment district with high population densities (600-800 persons per hectare). It is home to residents with economic classes ranging from low to medium, and it can be considered a tourist attraction and one the most traditional areas that remain popular in terms of the socio-cultural morphology. These attributes can be observed through the characteristics of

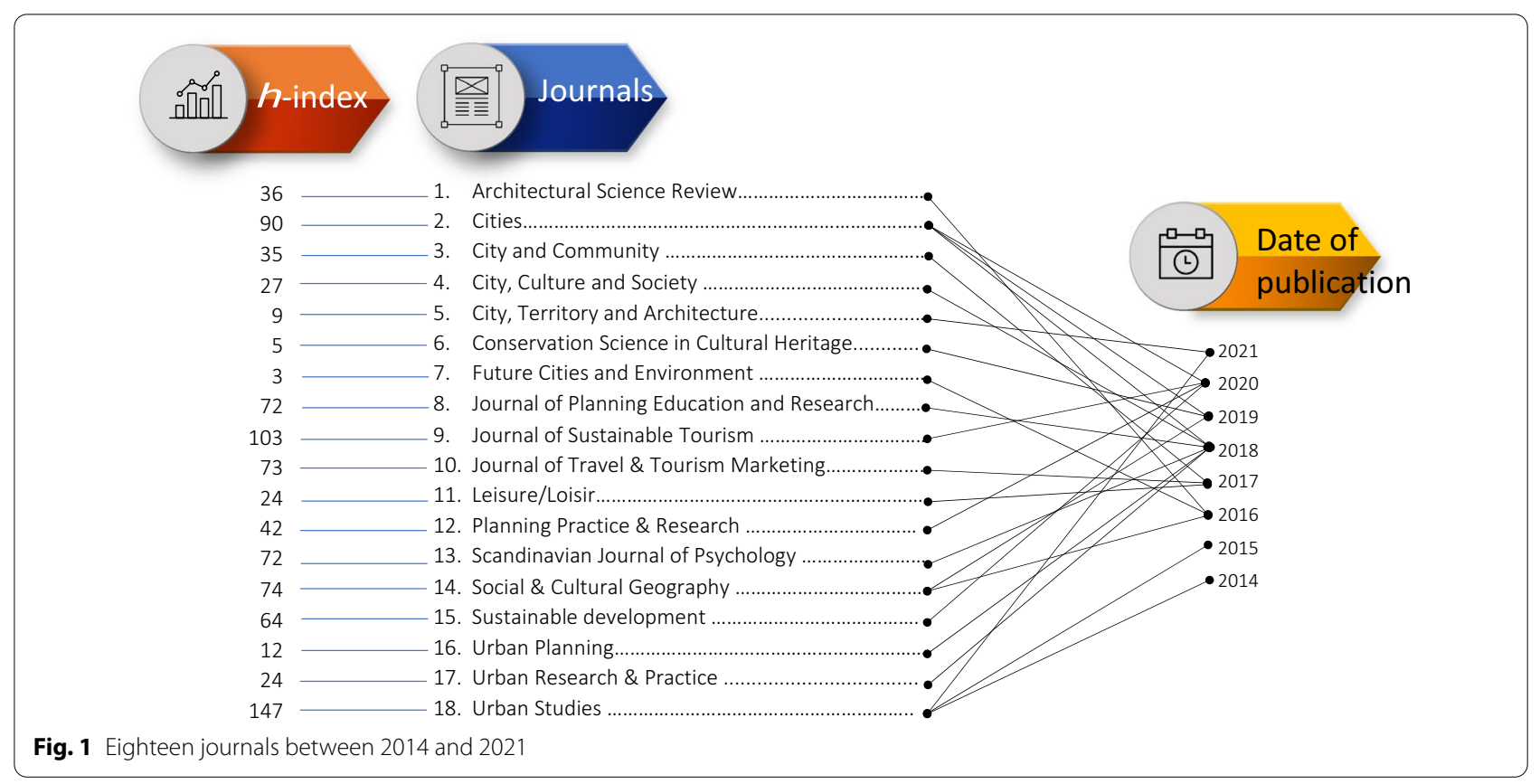




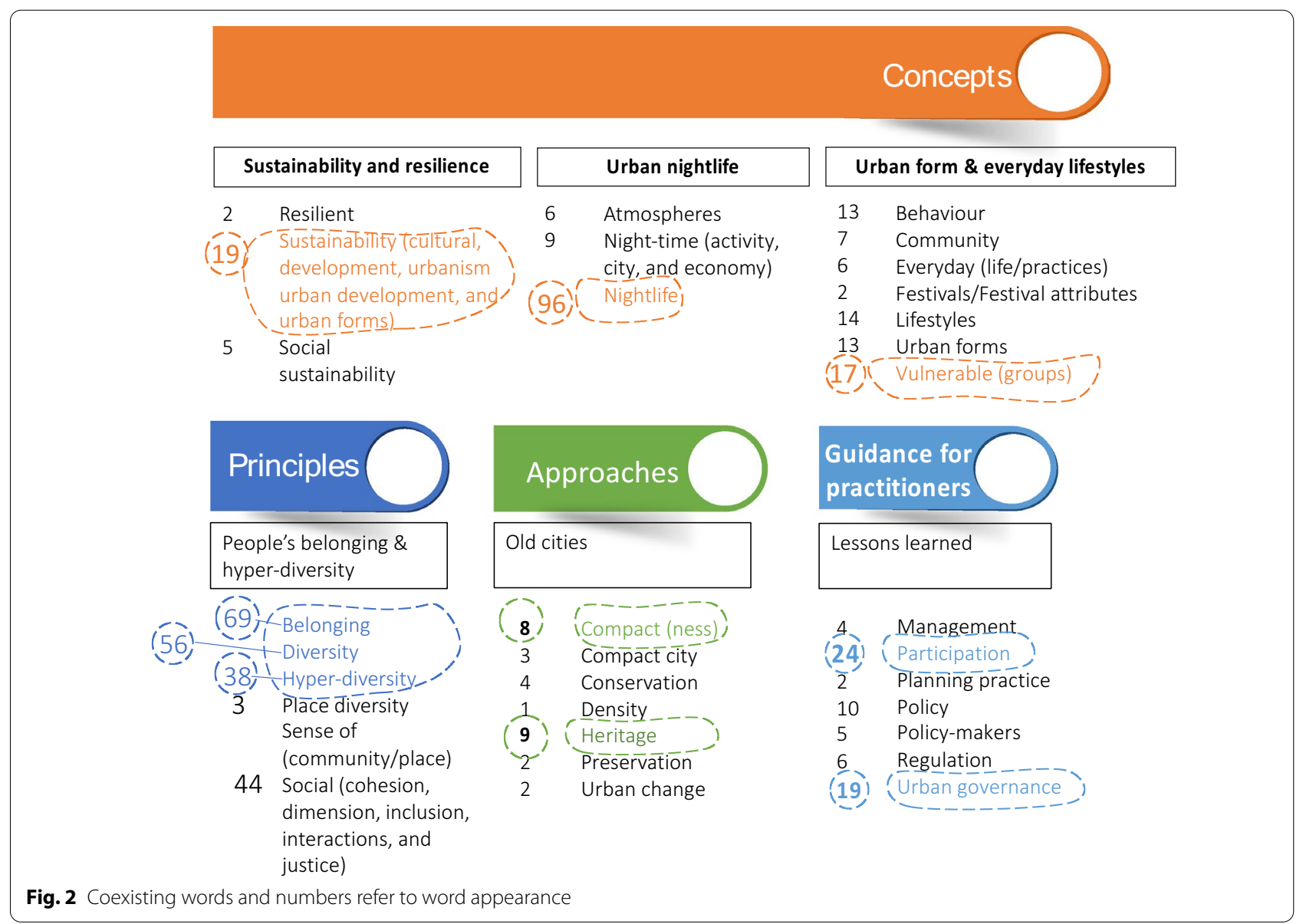

the population, such as clothing, food, activities, behaviour and attitudes. Al-Gamaleya District encompasses various types of professions, such as public and private sector employers, small private businesses and street vendors.

Over time, especially at the end of the twentieth century, developers of the Al-Hussein districts' urban fabric maintained compact, dense tissue characteristics as much as possible. Nevertheless, many changes occurred owing to unplanned projects and spatial encroachments, especially in terms of the hyper-diversity of activities.

The residential area in Al-Hussein seems similar to traditional residential places in terms of its functions, activities, urban form and lifestyle. However, the residential district characteristics in $\mathrm{Al}$-Hussein in terms of urban form and those of many communities in Old Cairo (Historic or Fatimid Cairo) appear to be traditional residential areas. In fact, Al-Hussein Square only slightly differs from its counterparts in built-up districts in terms of jobs, activities, urban form and nightlife. The urban form of Al-Hussein not only exerts a substantial effect on nightlife transformation but also changes with the over-diversification of the transformation in night-time activities. Figure 4 shows the urban form of Al-Hussein public place (as a case study) in an abstract form and the changes in the hyper-diversity of the building uses and activities.

\section{Ethnographic and participatory study}

In ethnographic research, two methods-namely, direct observation and semi-structured interviews with residents, workers and visitors-can be used to investigate various challenges.

The outdoor public space of Al-Hussein Mosque in Old Cairo is a suitable setting to conduct direct observation. This area was selected based on the regular visits conducted by the authors on Fridays for familiarity for data collection. The authors conducted observations on Friday evenings for 3 months (April to September 2020), mostly from 7:00 PM until midnight. Fridays and Saturdays are considered days off for employees in several formal institutions in the Middle East and Northern Africa. During the study period, Ramadan (a Hijri month in the Islamic 

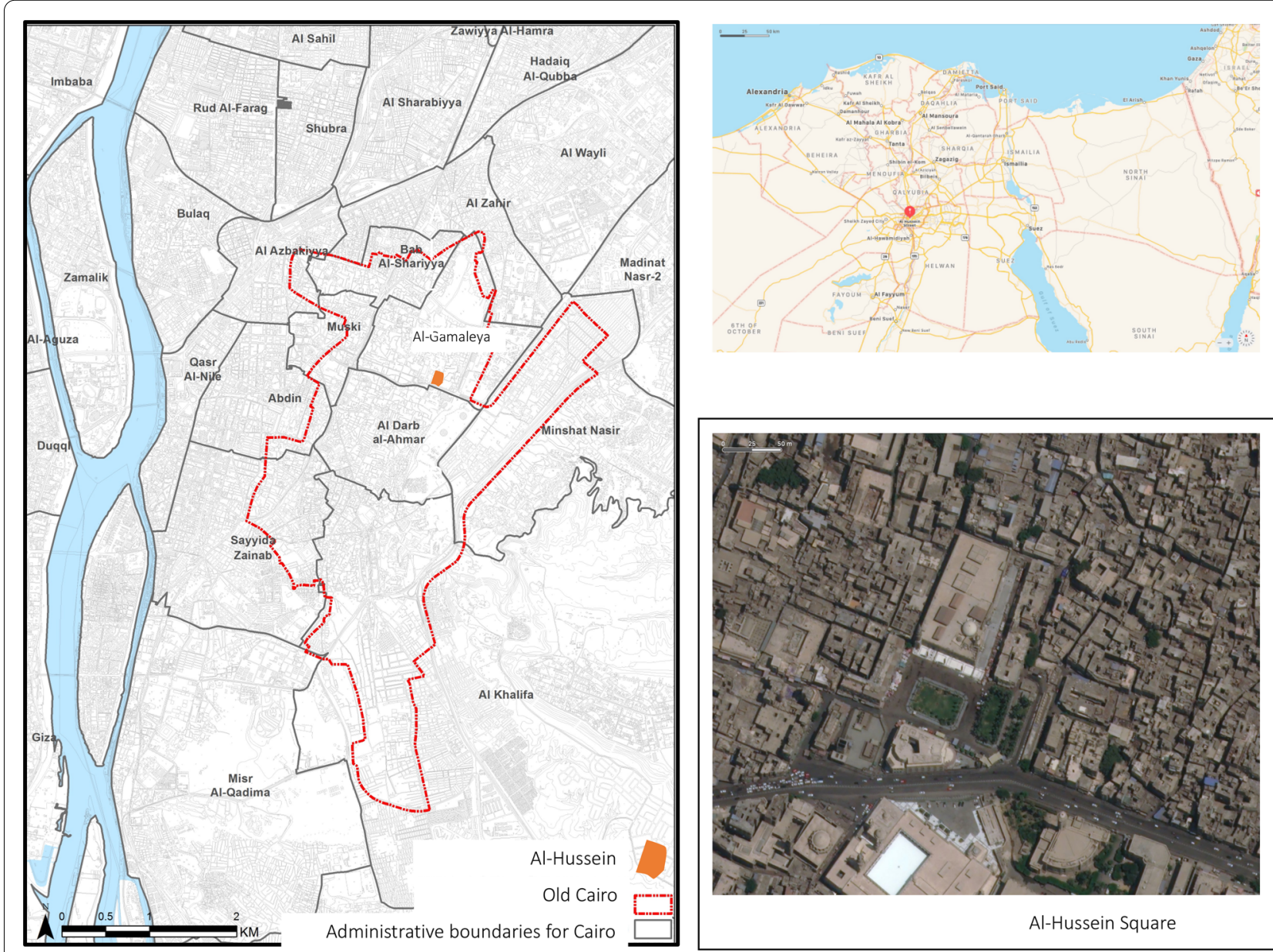

Al-Hussein Square

Fig. 3 Location of the case study of Al-Hussein Square

calendar) was celebrated in Arab countries (from 23 April to 23 May 2020).

Ramadan is one of the most significant religious, cultural, festive and recreational event in many cities. Ramadan is the fourth pillar of Islam, when Muslims are required to fast from sunrise to sunset. Frequently, many Muslims venture outside their homes to take Iftar (meals eaten by Muslims after sunset during Ramadan) and Suhor (late meals before starting the feast) in restaurants and cafes scattered in the public spaces. The nightlife in certain historical sites around downtown Cairo lack documentation. Generally, small-scale venues comprise monuments and buildings, such as Al-Hussein Mosque.

Selecting such context for observation enabled the authors to document the changes that occurred in nightlife activities, especially the hyper-diversity of nightlife activities in public spaces. We adhered to the definition of diversity and intensity of activities after identifying the indicators of excessive diversity from theoretical studies (Abusaada \& Elshater 2021a; Campo \& Ryan, 2008;
Elshater et al. 2019). We observed and recorded the behaviours of residents and visitors.

The study obtained information about the reactions of residents and visitors to the variables of hyper-diversity in nightlife activities. The authors developed a semistructured interview through a random sample of eight residents and workers in commercial and recreational places and four visitors. The interviewees were divided into two groups according to their reason to visit. The interview focused on the following questions:

1. Does the hyper-diversity of nightlife activities in public spaces improve or threaten nightlife?

2. Does the absence of vulnerable and non-affiliated groups in decision-making increase the hyper-diversity of nightlife or threaten it?

Additional data were collected to address the gaps in our data through a limited interview with random samples of residents and workers in the commercial and 

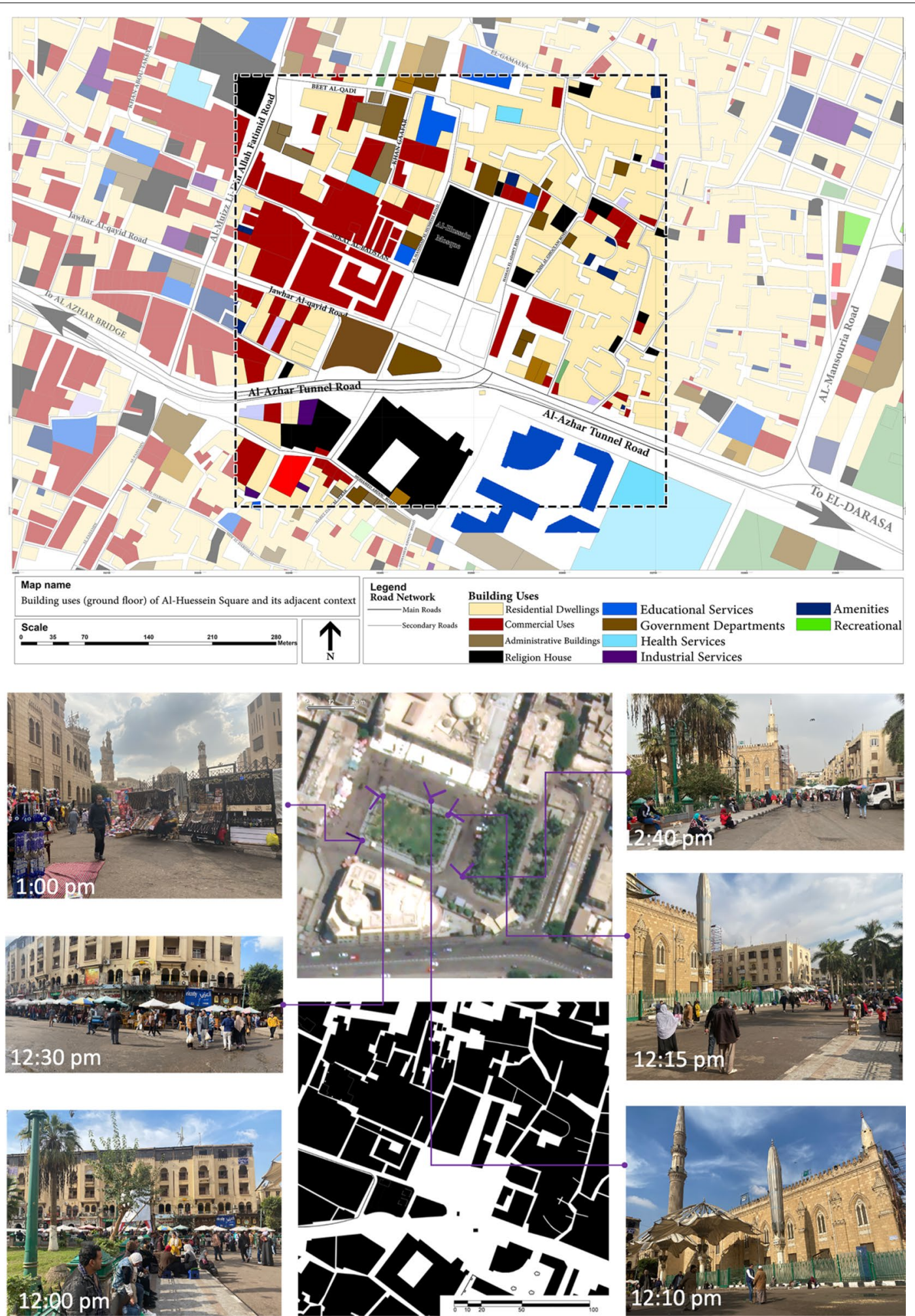

Fig. 4 The hyper-diversity of the uses and activities and the abstract of urban form (figure and ground) 
recreational places and some visitors. The interviewees were also separated into two groups based on their needs. The interview focused on the above-mentioned questions.

Focus groups discussions were led by the researchers. Responses from the interviewees were grouped into two categories. The first focused on functional transformations, which are particularly related to the chaotic use of public spaces at night, while the second highlights the visual and aesthetic dimensions related to the hyperdiversity of activities on the facades of residential, commercial and historical buildings.

The subsequent two sections discuss the results: the first reviews the selected articles and offers recommendations about improving nightlife, and the second describes the design and experience of Cairo as a case study.

\section{First Results: Deductive argument in terms of nightlife and hyper-diversity \\ Definition of hyper-diversity and its relationship with belonging}

Previous studies have defined place diversity as a form of social and economic mixing, that is, the combination of people with different incomes, races, household sizes, lifestyles and non-residential activities with other uses and functions of the land. In this research, diversity denotes the dynamics, behaviour patterns, lifestyles and activities of individuals, which add to various daily experiences (Tasan-Kok et al., 2014). Hyper-diversity focuses on the dense diversity of the population in terms of lifestyle, attitudes and activities (Kraftl et al., 2019). The extent of its strength or weakness is evident through interactions between society members according to their behavioural situations, which are governed by the following criteria: sense of belonging, dealing with strangers and willingness to participate. The literature documents four concepts associated with hyper-diversity, namely, social cohesion (Ahmadi, 2018), social mobility (Alipour \& Ahmed, 2021), economic performance (Kalinauskaite et al., 2018) and governance (Hadfield, 2015). Some studies have discussed three theoretical foundations, namely, financial health (Hassan et al., 2016), social equity (Nguyen, 2018) and sustainability (Ballet et al., 2020; Bibri et al., 2020; McClinchey, 2017; Seijas \& Gelders, 2021).

In city planning, some studies found that structural and repetitive confrontations could eliminate stereotypes and challenge prejudice (Fu et al., 2017; Sakamoto et al., 2018; Sharifi, 2019). Investigative studies proposed that familiarity with diversity is essential for stimulating a sense of 'home' in multi-cultural and multi-ethnic communities (Kohon, 2018). Against this background, this study defines the variety and hyper-diversity of people and places (Peterson, 2016). Social diversity occurred because of globalisation and the influx of immigrants into European and North American countries. These groups intended to obtain better community services (Dean et al., 2018) but may face challenges in nightlife activities (Nofre et al., 2017). Thus, the study investigates these challenges.

\section{Changes in the characteristics of old cities during nightlife}

Nofre et al. (2017) and Kalinauskaite et al. (2018) showed that marginalised societies and those who feel that they do not belong to a place may experience significant social impacts, especially in terms of nightlife. These studies compared the behaviours of permanent residents and new consumers of the nightlife in the district of Bairro Alto, Lisbon, and found that expansion and commodification are among the most influential factors that change the characteristics of nightlife. Moreover, Kalinauskaite et al. (2018) confirmed that diversity, unfamiliarity and lack of awareness of behavioural norms may increase aggression in night-time events in North Brabant, Eindhoven, the Netherlands. Moreover, crowded streets and filth in the environment strongly affect people's mood.

To enable urban governance in a night economy and a more inclusive city, urban strategies should address prevalent issues, such as licensed buildings saturation, alcohol-based definition of the night economy and dialogue and cooperation between city governments and the nightlife industry (Seijas \& Gelders, 2021). The literature on managing nightlife transformation has used complex methods to gather data and plan mechanisms in order to address nightlife problems (Hadfield, 2015), such as overcrowding, noise levels and traffic congestion (Abusaada \& Elshater, 2021b, 2020). Moreover, previous research recommends that the nightlife economy should develop laws and regulations using software to facilitate mobility, reduce noise and enhance compatibility between users of outdoor places (van Liempt et al., 2014; Talebian \& Riza, 2020; Yun, 2021).

\section{Guidelines for improving nightlife in terms of urban governance and decision-making}

According to a systematic review, the following urban toolkit includes techniques to assist practitioners and policymakers with development plans (McClinchey, 2017). This toolkit aims to achieve a liveable, resilient and safe nightlife in public places in the districts of the old city. Moreover, it interprets the participants of the current ethnographic study. The kit includes three tools.

The first discusses the hyper-diversity of nightlife activities in public spaces and focuses on the behaviour of 
long-term residents, expat workers and out-of-place visitors and provides five pointers:

1. Articulating the hyper-diversity of activities according to the complex relationships between the urban environment and control based on people's everyday life patterns (Tasan-Kok et al., 2014).

2. Recognising spaces for accommodation and intermingling to enhance place belonging (Tasan-Kok et al., 2014).

3. Identify the principles of the hyper-diversity of activities based on the relationship between people and places (Dean et al., 2018; Kraftl et al., 2019; Peterson, 2016).

4. Navigating public spaces based on familiarity (Peterson, 2016):

- Familiarity provides a sense of safety and control.

- Familiarity with diversity stimulates a sense of home.

- Physical and social proximity enable people to feel at home and connected to others.

- The context of hyper-diversity is related to the forms of collective lifestyle.

5. Discussing the aspects affected by the hyper-diversity of activities during daily performances, materiality and emotion that articulate and produce social differences, such as on-shop fronts and lampposts (Kraftl et al., 2019).

The second tool focuses on the necessity of urban participation/public involvement with policymakers in presenting urban guidelines. This phase focuses on five pointers:

1. Preventing chaos that violates the stipulated requirements, particularly during festivals (Fu et al., 2017):

- Preventing changes in urban form, land use and activities:

- Organising festive events in a manner appropriate to the historical context.

- Involving residents and visitors in organising and directing the events.

2. Preparing progressive and balanced sustainable development plans (Nguyen, 2018):

- Striking a balance between modern requirements and the preservation of history.

- Striking a balance between multi-cultural visitors and the stability of residents.
3. Preventing inequalities and social exclusion by guiding citizens (Kohon, 2018).

4. Supporting urban participation and involvement (Chen et al., 2020; Nguyen, 2018):

- Promoting public involvement in the value assessment of heritage (Megeirhi et al., 2020).

- Emphasising the local citizens' sense of place and daily life.

5. Expanding the notion of nocturnal governance (Seijas \& Gelders, 2021):

- Ensuring social order after dark.

- Mediating and collaborating between socio-economic and cultural issues.

The third tool focuses on guidelines for entertainment zones, nightlife atmosphere, night spaces, urban change, unplanned nightlife and artificial lighting (Campo \& Ryan, 2008; Kalinauskaite et al., 2018; Nofre et al., 2017; Talebian et al., 2020). These guidelines intend to improve the nightlife in public places in old communities in relation to night-time planning (Seijas \& Gelders, 2021) and heritage assets (Chen et al., 2020). This tool follows four guidelines:

1. Improving, developing and upgrading the historical context to achieve high-quality performance and liveability.

2. Emulating the heterotopic qualities of entertainment zones (Campo \& Ryan, 2008):

- Physical and experiential qualities project a unique nature.

- Physical and experiential characteristics should be considered.

- Probable economic and social benefits have financial returns to citizens.

- Transformation of downtown places from being dangerous to exciting.

3. Enhancing the economy, socialisation, identity creation, and nightlife leisure (van Liempt et al., 2014).

- Establishing drinking experiences, cultures and urban atmospheres through spatiality.

- Respecting territoriality, that is, 'being in an environment where people behave similarly' and appreciate its implications.

4. Harnessing the territorial capital as represented by heritage assets for the benefit of the current and 
future societies, which influence complex frame planning practices (Kohon, 2018) and actions (Chen et al., 2020) from the institutional, cultural and socioeconomic contexts:

- Providing immediate action plans that drive changes in urban form.

- Securing government funding to advance conservation planning objectives.

- Promoting development strategies and local governments for projects that combine heritage, local development and amenity goals.

- Avoiding fake restoration with 'no attempt to depict the new as original'.

\section{Second results: observing hyper-diversity in activities during nightlife Indirect observation}

The morphological transformations have two dimensions. The first is physical, which includes (1) road traffic networks and pedestrian movement on arterial roads, local streets, underground tunnels and public/open spaces and (2) the construction transformations of architectural buildings, mainly historic buildings surrounding the public square of Al-Hussein Mosque. The second is the non-physical dimension, which describes the demographic and socio-cultural characteristics that encompass nightlife transformations.

The Al-Azhar Tunnel is the primary traffic network in Old Cairo, separating the site into two parts. The first includes the Al-Azhar Mosque, Al-Azhar University and Al-Hussein Hospital on one side. The Al-Hussein Mosque and the public square are on the other side of the road. This public space attached to a commercial area known as the Khan al- Khalili bazaar area and the North El Gamaleya axis, resulting in the partial removal of the Bab Al-Nasr Cemetery. The central public space is located in the front of the Al-Hussein Mosque and governmental office buildings. On one side, a small garden lies at the front of the mixed-use buildings, while the other side features the Al-Hussein Touristic Hotel with services and recreational shops on the ground floor, such as Al Dahhan Restaurant, Abou Hamza Canter Cafe, Elzahraa Cafe and Restaurant, Layaly al Hussien cafe, $\mathrm{Al}$-Hussein Bazaar and a pharmacy. Figure 5 shows the activities in $\mathrm{Al}-\mathrm{Al}$ Hussein Square.

The design of governmental, residential and entertainment establishments emphasise the painting of facades in uniform colours. Historic architectural details are overlooked such that several monuments have been substantially altered. In front of the mosque, an electronic canopy was constructed for people gathering to pray. A small garden is situated at the centre of the square enclosed by fences to prevent pedestrian access to this small garden. Many benches are placed nearby for resting.

Most of the lifestyle transformation occurred in the twentieth century and progressed in the last two decades. These changes occurred because of the widespread use of technology. However, the majority of dissatisfaction with the place is mainly with the changes in shop owners on the one hand and the actions of neighbourhood engineers in local municipalities that changed the lifestyle on the other hand, besides the complaint of employees in the streets, street vendors and beggars. The Al-Hussein district implemented many development projects. Ironically, in 2017, a new development project was launched, which targeted three axes. The first is constructing a mosque to encompass a significant number of worshipers by expanding its internal architectural space, building a basement and allocating a part of the public space to become a covered outdoor courtyard for prayer. Moreover, Al-Hussein Square provided space to facilitate entry and exit to the mosque. The second is preserving the aesthetics and decorations of the mosque, such as restoring facades, minarets, wooden ceilings, internal lighting systems and places of ablution. Al-Hussein Mosque included the external courtyard. The third is orienting all pedestrian traffic lanes, green areas and vertical mobility to the Qibla direction. Furthermore, public space in the surrounding context was developed in terms of urban design or landscape architecture.

An indirect observation may determine the choice of the data collection method. Recently, the changes that occurred in the public space make it seem unorganised and spontaneous to meet the requirements of each landlord or tenant. These changes occurred in the following context: the facade of the historic mosque and ancient and modern buildings overlooking the space, such as shops, restaurants, cafes and juice shops. The violations in terms of the ownership of public spaces appeared in the external extension of each store in the public space and on pedestrian traffic. The mosque's open public space was designated for external prayer, the al-Midan Park, and movement paths. Vertical and horizontal plantings (palm and grass) are situated in the middle of the public space with fences separating the mosque from the public space, passers-by and street vendors. Moreover, furnishings were placed that appear in the stalls and on the outside fences of street vendors.

\section{Ethnographic and participatory findings}

Many respondents were invited for the interview. The hyper-diversity of activities did not represent an issue that deserved discussion among many of the participants. 

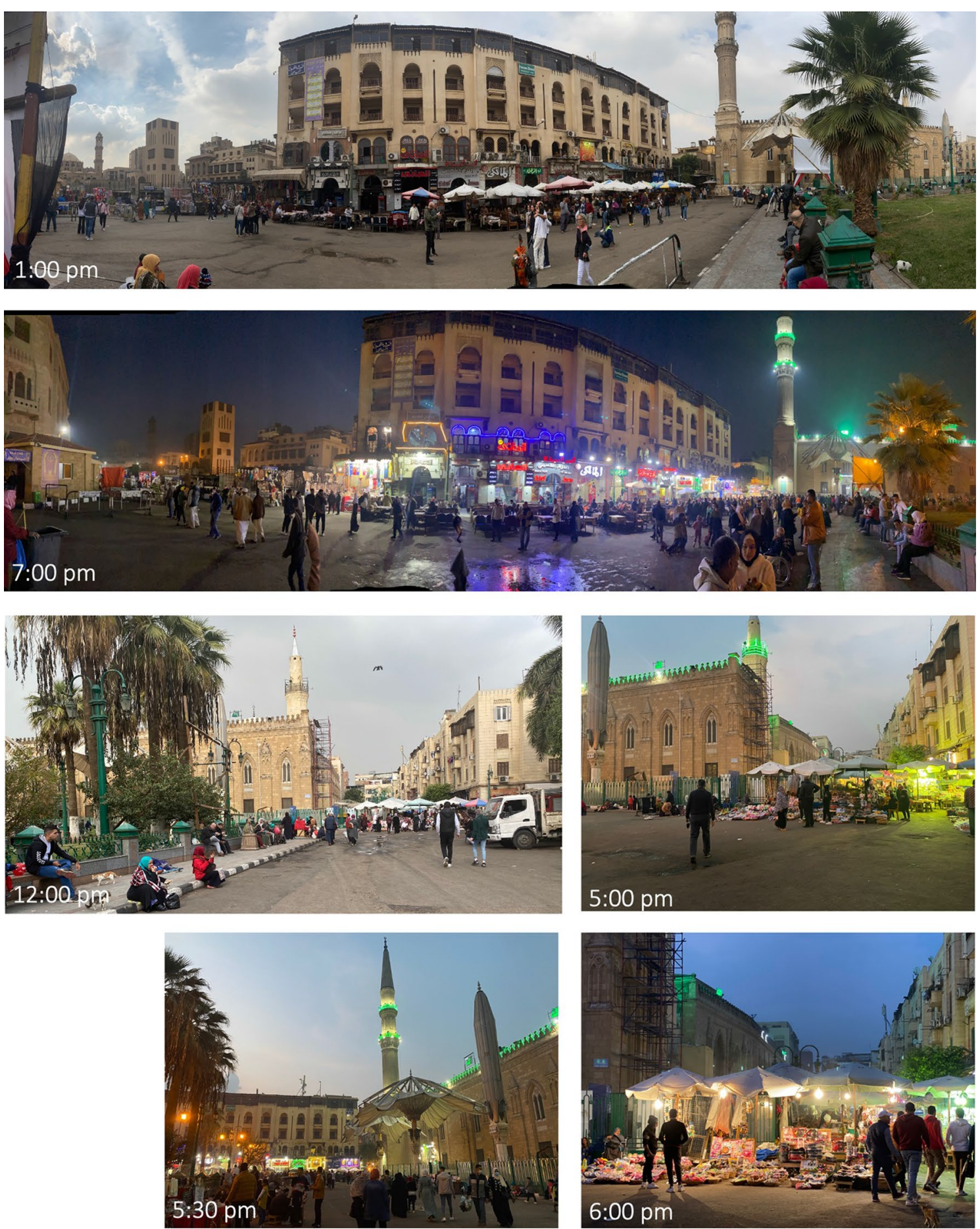

Fig. 5 Al-Hussein Square contains different types of spatial encroachments, owing to the hyper-diversity of activities

As one participant said: '[...] The beauty of Al-Hussein district includes everything needed for recreation, prayer and food (fat and sweets) and juices, .... The entertainment does not end with playing dice, dominoes and cards, and whoever wants it, the best smoke is sold here. All kinds of smoke'. Moreover, another participant stated that ' $[\ldots]$ the mixing of people and their closeness to the Iftar and Suhor tables make you feel as if you are with your family and make you feel reassured, and happy'. Another participant came and intervened in 
the conversation, '[...]. Never forget the spiritual atmosphere that blows on us from Al-Hussein Mosque ... that is, something for God, Hussein'. At the time, the question regarding threatening nightlife seemed to be pure fiction.

Participating in development projects seemed normal for expatriate workers because they do whatever they want for commercial and recreational benefits. They move around their vital business environment without violent interference from the local governments or in a manner that does not limit their freedom. Initially, comments from lifelong residents focused on two main themes: functional transformations, especially in the chaotic use of public spaces at night, and the visual and aesthetic dimensions linked to the over-diversity of development projects. Most residents expressed that the redevelopment projects primarily focused on solving traffic movement regardless of other problems, such as those related to street vendors and beggars. In a different vein, the residents believe that the nightlife is bright and that visitors strongly cooperate. Moreover, visitors enjoy the night tourism activities, such as sightseeing old monuments, experiencing folklores and dining, entertainment and shopping. Many participants said, 'We are delighted with this place.' This theme pertains to the engineers of the municipality, which focus on urban form changes without considering the needs or desires of the residents. This issue revolves around how certain residents discuss their sense of belonging to the $\mathrm{Al}$-Hussein public space:

I like this place during night-time so much, and I visit it every year more than once. [...] Indeed, I do not believe that the on-going transformations from day to night time or even during any part of the year make me lose my sense of belonging to this place.

Other participants mentioned the following:

In recent years, I noticed that many changes have occurred, which are pronounced in lighting systems during night time. [...] I agree with you; the arrangement of night lighting units in the field is messy, which seems to be done personally and without prior design. [...] Let me add that technology is changing fast, but I have no idea about its effects on visitors' sense of belonging to the place.

I do not know what you mean by smart places, [...], but it is full of computers and digital advertising if you are talking about technology.

Many owners explain their sentiments about the impact of hyper-diversity in the public space:

I owned my bazaar more than 40 years ago; I feel that the ethnic differences between both residents and visitors in this place are highly appreciated.
[...] In fact, I see there is no real change; in this case, Egyptians are among the people who value difference. [...] We are distinguished for being multi-ethnic, as you know.

However, a remarkable comment from many residents and visitors was, 'Why you are asking about sense of belonging'? Before we responded, they added that they belonged to the spirit of these places despite the changes. Although this expression demonstrates the extent of their love and ideological attachment to the place, it provides a clear reflection of the majority's lack of knowledge about their basic right to develop the places. However, the responses indicate the prevention of all negative aspects that they may have been exposed to because participation is essential. Another remark is that leaving the place does not mean one stops belonging to it. In other words, although many locals left their original place of residence and moved to other places, they remain emotionally and spiritually connected with their land of origin. Moreover, a confusion initially exists between conventional and smart technologies. Many interviewees believed that the canopy, lighting, billboards and automated teller machines in front of the mosque were evidence that the place had become quasi-smart. Further, they considered that these technologies made a positive contribution to the place and that they enhanced the charm of the monuments.

Old Cairo is the ancient nucleus from which presentday Cairo expanded. Although this old part of Cairo has been subjected to many changes throughout history in terms of civilisation, architecture and activities, it has retained its historical identity. Presently, projects for new urban development are influencing the enormous emotional flow towards the place. Specialists are split into two groups: those who advocate and those who reject the current events in the old district. Advocates welcome the growing interest of residents and visitors to these places. Meanwhile, defenders view this type of development (i.e. compact cities) as one of the most appropriate responses to the requirements of the modern technological age. Conversely, the refuseniks believe that several residents and visitors have lost their sense of belongings because they refuse to participate in development projects.

\section{Discussion and conceptual framework}

This article is a research on urban studies that focuses on old neighbourhoods with a historical dimension, especially Old Cairo. It is written with urban planners and designers in mind and offers a conceptual framework for improving nightlife to provide support to the locals, especially vulnerable and marginalised groups, and their sense of belonging to the place. This study examined 
the effects of the hyper-diversity of nocturnal activities in public spaces and their role in reconstructing urban nightlife experiences by preserving urban form as an active component of urban governance laws. The abovementioned short review highlights the fact that less is known in the recent literature about changes in terms of urban form owing to the hyper-diversity of activities in public spaces in old cities. Moreover, the study examines why and how citizens, whether residents or visitors, lose their sense of belonging, especially towards nightlife transformation.

The current study confirms that urban form changes with the over-diversification of the diversion in nighttime activities, leading to changes in urban nightlife, which may not influence the affiliation of people to public spaces in old neighbourhoods with a historical dimension. This affiliation is dependent on the societal, cultural, social and economic forces that transcend the transformation of the built environment. The challenging problem in the issue of the sense of belonging to public spaces refers to how one recalls these spaces because of unplanned projects and spatial encroachment, which gradually occurred in public spaces.

The prevalent problem in the hyper-diversity of nightlife activities in public spaces refers to how one loses emotional focus towards these communities. The results of the present study have presented three factors of changes in urban form: (1) successive development projects, which are incompatible with approaches for preserving areas with a historical dimension in many cases, (2) expatriate workers who conduct activities in surrounding public places and are frequently unaware of the basics of place preservation because of differences in personality and cultural background and (3) new residents in residential buildings surrounding the site, the majority of which are expatriates from various areas who work in those areas and have replaced long-term residents.

These results indicated that the feeling of belonging is not causally related to the change in nightlife experiences as a result of the hyper-diversity of activities, despite their increase and presumed attack on the place. Although the sense of belonging will remain extraordinarily strong, the result in terms of dissatisfaction with the current events ranges from leaving the place (permanent residents) to the lack of intent to revisit, in the case of visitors.

These differences between loss of affiliation and dissatisfaction are related to two issues. The first is the ability of people in adapting to different types of activities that are suited to nightlife needs. Successful conservation approaches have linked the fundamentalism of historical public spaces with the evolving needs of the people. The second issue pertains to the role of people to participate in development projects and preserve the place, which is a stakeholder role in local communities. A substantial understanding of how a site will address these issues depends on the power relationships and interests of stakeholders, such as government agencies, permanent and new residents, expatriates (marginalised groups) and visitors. The spatial configuration is closely related to the patterns of the hyper-diversity of activities and continued intervention to the urban forms of public spaces. Several new residents and expatriate groups insist that this aspect is unrelated to the sense of belonging to the place, and many of them adopted this opinion about the sense of belonging primarily because of its religious and historical values.

In terms of changes in nightlife, the interviewees asserted that they differed only in style, Ramadan settings, restaurants and cafes. However, many respondents stated that the Ramadan nightlife characterised these public places in ancient times. Thus, they are an ancient religious tourist attraction not only during the month of Ramadan but also during the celebration of the birth of Al-Hussein Ibn Ali (the grandson of Prophet Muhammad from his daughter). In historical sites, which are deeply rooted in religious influences, these shifts in the atmosphere of the nightlife do not influence the sense of belonging. However, the participation of people in formal and informal changes plays an important role in terms of rethinking the nightlife atmosphere, reflecting the compatibility of historical sites and nightlife over time.

Consistent with previous studies, the inconsistency between the chaotic interventions in historical sites in terms of urban form, such as tangible (physical) elements (lighting and billboards in public spaces) (Berardinis et al., 2015), whether traditional or contemporary, with the characteristics of urban environments is worthy of discussion. This inconsistency exerts a considerable impact on unplanned nightlife (Campo et al., 2008), which may lead to the loss of a sense of belonging (Pinkster, 2016) for residents and visitors. Comparing our results with those of previous studies, we found that the problem is that these interventions appear in two aspects. The first denotes the similar findings regarding the patters on the negative aspects of the inability to adapt to the context, which was exacerbated during and after development projects (Megeirhi et al., 2020). The second is the chaotic interventions of citizens, whether residents or owners of commercial and recreational spaces. Compared to the present study, previous studies suggested that urban nightlife in public spaces changed because of the residents' spatial encroachments or visitors' aggressive behaviour, such as 'harsh interactions between people, or frustration-induced pushes and verbalizations' (Kalinauskaite et al., 2018, p. 224). Moreover, Peterson (2016) noted that the hyper-diversification 
in peoples' lifestyles, attitudes and activity patterns can complicate their sense of belonging (Berzano \& Genova, 2020). Meanwhile, Pinkster (2016) implicitly confirmed that the hyper-diversity of activities led to a loss of belonging: 'collective memories and shared symbolism of community' are crucial to belonging (p. 18). Several studies have demonstrated that the relationship between the hyper-diversity of activities and sense of belonging, especially at night, is relevant to the municipalities' authority (Seijas \& Gelders, 2021; Abusaada et al., 2021). Moreover, the negative impacts of spatial encroachment may be latent in terms of citizens' participation in development projects (Sakamoto et al., 2018).

\section{The four Ps in the conceptual framework}

This study provides suggestions for policymakers for informed decision-making in improving nightlife through the participation of vulnerable groups. A conceptual framework has been established based on stakeholders' positive and negative responses in terms of two issues. The first is supporting the local authorities in urban participation in all development projects (Ahmed, 2018). The second is drafting laws that limit unplanned interventions and abuses by stakeholders and spatial encroachments as well as aggressive behaviour of marginalised groups.

Therefore, conducting observation and random interviews was useful in understanding how the population valued their urban origins and their awareness of changes induced by marginalised groups. In this context, urban form exerts a strong effect on nightlife transformation. Moreover, the results indicate that the range of the hyper-diversity of activities, such as unplanned projects and spatial encroachments, can increase the loss of sense of belonging in public spaces in the city's old communities. The conceptual framework involves two phases on exploring and initiating the improvement in nightlife through 4 pillars, namely, predicting, proposing, preparing and preventing, which include 12 steps (Fig. 6):

\section{Stage one: Exploring the positive and negative aspects}

I. Predicting the unplanned interventions of urban form and spatial encroachment at present and in the future by providing a detailed overview of (1) the goals of the local authorities and other stake-

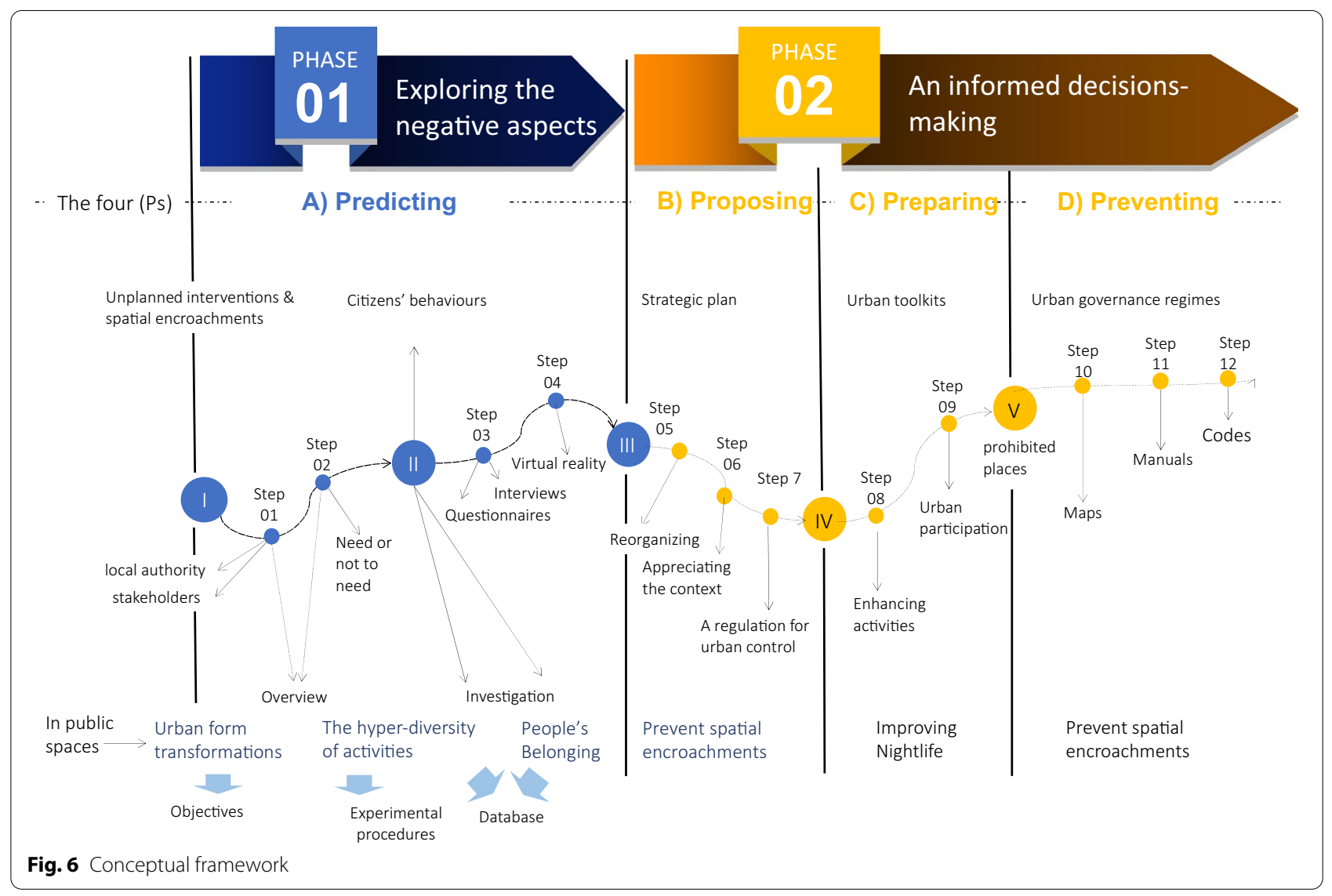


holders on the transformation that influence urban form and (2) the experimental procedures during the investigation of the need (or un-need) for the hyper-diversity of activities.

II. Predicting the behaviour of long-term residents, expatriate workers and visitors through a database that includes (3) the results of questionnaires and interviews with citizens to determine the extent of their sense of belonging to the place and their perceptions of hyper-diversity. Lastly, (4) virtual reality programs should be created based on all data and expectations should be formulated.

\section{Stage two: Informed decision-making}

III. Proposing a strategic development plan related to the hyper-diversity of activities by (5) reorganising the hyper-diversity of activities in each urban space at present and in the future, (6) appreciating the current context to meet future needs and (7) formulating a regulation for urban control to prevent spatial encroachment.

IV. Preparing guidelines to improve nightlife based on participation by (8) enhancing the efficiency of economic, socio-cultural and technological activities, (9) increasing the involvement and awareness of stakeholders, such as local authorities, residents, owners of shops, workers and visitors.

V. Preventing future encroachments that impact urban form by (10) preparing a map of prohibited places for violations of citizens, (11) creating a guide for prohibited places for future encroachment and (12) framing urban governance schemes by establishing laws and regulations to prevent encroachment.

\section{Limitations and future research}

Despite its success, this study has its limitations. While studies on urban governance and sense of belonging are abundant, research on the link between them and urban form and nightlife change is limited. Prior studies are limited to a subset of data collected from a few published articles in international journals. Therefore, future studies should consider unpublished or grey literature, such as research reports, government reports, dissertations, webcasts, poster sessions, presentations, conference proceedings and PowerPoint presentations. Two of the study limitations are the ability of the authors and availability of data. Furthermore, this study is limited to the authors' experiences and knowledge in identifying transformations in urban form in the study area. Thus, future studies should determine changes over time in certified historical documents, such as governmental digital maps and photographic documentation of the place from previous studies to avoid subjectivity and bias.

However, data availability will remain a challenge for studies that evaluate changes in urban form at the local level in some Global South countries. However, this study focused primarily on public spaces in Old Cairo. Future studies can include more public spaces in different situations to explore the hyper-diversity of activities related to the shift in social cohesion and thus potentially prove the findings recorded in this article. Such studies can follow the same process to identify the subjective factors that affect the sense of belonging in other living environments, such smart and sustainable cities.

Owing to the lack of funding and human resources, the semi-structured interview results are based on only 12 participants. Therefore, we recommend that subsequent studies conduct a year-round survey to improve the findings' accuracy and obtain opinions from more visitors during other seasons. Additionally, there is a severe limitation associated with the lack of investigating the implications of the hyper-diversity of activities and the sense of belonging associated with the participants' role. Furthermore, the proposed method considers the digital methods and accounts for the degree of importance depending only on limited interview data from five experts to define the results presented in this paper.

Therefore, to generalise the aforementioned influence on the urban toolkits' conceptual framework, studies that consider a broader expert range of participants and a wider spread of metropolitan areas with more diverse functions are required. Besides, as the boundary of participants' responses was pre-selected, there is a possibility of bias in the interview questions.

\section{Conclusions}

Lack of knowledge of the hidden potentials of differentiations is a topic worth exploring. This lack of knowledge correlates with the concept that citizens cannot make their own decisions. This study discussed how citizens welcome changes in their public space and sympathised with peers, even if the results do not fit many paradigms in urban planning and design. However, this study can accept claims that accommodating citizens' reactions to their public space is essential to understand and study to generalise the most appropriate. This aspect is better than imposing designs that do not suit citizens' intellectual orientations. Even if this study is limited and falls short of the ideas and practices of academics, the experiences that occur within cities include citizens, residents or visitors and key stakeholders, and each factor plays roles related to two changes, namely, urban form and the 
metamorphosis of nightlife. This study investigated the phenomenon further and endeavoured to eliminate the current challenges to engaging with complex aspects, experiences, atmosphere and sense of belonging.

These constructs interact with changes in urban form and public spaces. However, a closer inspection of the literature reveals several research gaps and shortcomings. Despite the wealth of literature, studies on the impacts of these technologies on urban nightlife transformation are lacking. Notably, in terms of loss of belonging, a deeper understanding of these parameters is required to reconstruct atmospheres based on cooperation between citizens and local communities. This study makes three contributions to address public spaces in old communities with a historical dimension:

1. This study explained the concepts used in this article, such as hyper-diversity, sense of belonging, urban form, nightlife experience and urban governance. It identified the key aspects of the interaction between these concepts to demonstrate their conflicts and complications and how research objectives and lessons can be used to operationalise these concepts.

2. This study provided a thorough review of data on the relationship between urban form and nightlife and emphasised the necessity of social participation in contrast with changes in urban form.

3. Finally, with the current revival of interest in rehabilitation issues in historical sites, one of the disadvantages is focusing mainly on urban forms that ignore concepts such as social cohesion and social capital. Thus, examining the psychological nature of a place's users can enable gaining knowledge about cultural and social backgrounds and restraining from making meta-decisions that conflict with this nature, regardless if such decisions are consistent with the principles of high-quality design and planning. Several academics and decision-makers believe that they are more aware of the people who use the place. This study found that several decisions let to hit the wall by the users of the place. Additionally, some decisions struck the wall from users of the place even if they were sound and serve material interests because they were inconsistent with their lives or behaviour. Ultimately, this objective implies that examining the culture of societies is crucial before decision-making, even with the participation of several users, especially in terms of community education and enhanced cultural, social and economic levels to improve local communities.

The study results will be of interest to practitioners and policymakers in compact cities and students, educators, researchers and many others concerned with issues of hyper-diversity and place belonging. In conclusion, investigating urban nightlife in public spaces is valuable for understanding several physical and non-physical changes that occur in many historical sites in several Global South cities. However, the proposed toolkit at the conceptual level may require further development through empirical testing.

\section{Supplementary Information}

The online version contains supplementary material available at https://doi. org/10.1186/s40410-022-00150-9.

Additional file 1: Appendix S1. The coexistence keywords in the title and abstract of 26 articles in 18 Journals between 2014 and 2021.

\section{Acknowledgements}

Throughout the writing of this piece of work, the authors of the present work would like to thank our interviewees. This work has received a great deal of support and insights during the interviews. The authors also wish to acknowledge the editor and reviewers in City, Territory and Architecture for their constructive feedback and during the review process.

\section{Authors' contributions}

The authors, $\mathrm{AE}$ and $\mathrm{HA}$, of the present work declared that their role in conducting this research was distributed equally; they both conceived and designed the analysis and contributed to the data discussion. They also declared that the work presented here is solely on their own responsibility. All authors read and approved the final manuscript.

\section{Funding}

This research is funded by Science, Technology and Innovation Funding Authority (STDF) under the STDF Basic \& Applied Research Grants (STDFBARG), Basic Sciences Research Program, Non-Industrial Sector under grant number STDF-BARG 37234.

\section{Availability of data and materials}

The authors confirm that the data supporting the findings of this study are available within the article and its additional file.

\section{Declarations}

Competing interests

The authors declare that they have no competing interests.

\section{Author details}

${ }^{1}$ Department of Urban Design and Planning, Ain Shams University, Cairo, Egypt. ${ }^{2}$ Architecture Department, Housing and Building National Research Center (HBRC), Cairo, Egypt.

Received: 24 September 2021 Accepted: 26 January 2022

Published online: 10 February 2022

\section{References}

Abusaada H, Elshater A (2020) Urban design assessment tools: a model for exploring atmospheres and situations. Urban Design Plan 173(6):238255. https://doi.org/10.1680/jurdp.20.00025

Abusaada H, Elshater A (2021a) Effect of people on placemaking and affective atmospheres in city streets. Ain Shams Eng J 12(3):3389-3403. https://doi. org/10.1016/j.asej.2021.04.019

Abusaada H, Elshater A (2021b) Improving visitor satisfaction in Egypt's Heliopolis historical district. J Eng Appl Sci 68(1):1-22. https://doi.org/10. 1186/s44147-021-00022-y 
Abusaada H, Elshater A, Rodwell D (2021) Transforming urban nightlife and the development of smart public spaces. IGI Global, Hershey

Ahmadi D (2018) Diversity and social cohesion: the case of Jane-Finch, a highly diverse lower-income Toronto neighbourhood. Urban Res Pract 11(2):139-158. https://doi.org/10.1080/17535069.2017.1312509

Ahmed KG (2018) Instinctive participation: Community-initiated mechanisms for managing and maintaining urban poor settlements in Cairo, Egypt. Urban Res Pract 12(4):341-371. https://doi.org/10.1080/17535069.2018. 1451555

Alipour SM, Ahmed KG (2021) Assessing the effect of urban form on social sustainability: a proposed 'Integrated measuring tools method'for urban neighbourhoods in Dubai City. Territory Architect 8(1):1-21. https://doi. org/10.1186/s40410-020-00129-4

Ballet J, Bazin D, Mahieu F-R (2020) A policy framework for social sustainability: social cohesion, equity and safety. Sustain Dev 28(5):1388-1394. https:// doi.org/10.1002/sd.2092

Berardinis PD, Marchionni C, Capannolo L (2015) The urban lighting in the rehabilitation of the minor historical centre. The design scenarios for the architectural valorisation and the energy efficiency improvement of the urban environment. Int J Architect Technol Sustainabil 1:27-43. https:// doi.org/10.4995/vitruvio-ijats.2015.4473

Berzano L, Genova C (2020) Lifestyles and subcultures: history and a new perspective. Routledge, London and New York

Bibri SE, Krogstie J, Kärrholmd M (2020) Compact city planning and development: emerging practices and strategies for achieving the goals of sustainability. Dev Built Environ 4:1-20. https://doi.org/10.1016/j.dibe. 2020.100021

Campo D, Ryan BD (2008) The entertainment zone: unplanned nightlife and the revitalization of the American downtown. J Urban Des 13(3):291-315. https://doi.org/10.1080/13574800802319543

Chen F, Ludwig C, Sykes O (2020) Heritage conservation through planning: a comparison of policies and principles in England and China. Plan Pract Res. https://doi.org/10.1080/02697459.2020.1752472

Chmielewski S, Lee DJ, Tompalski P, Chmielewski TJ, Wężyk P (2016) Measuring visual pollution by outdoor advertisements in an urban street using intervisibility analysis and public surveys. Int J Geogr Inf Sci 30(4):801-818. https://doi.org/10.1080/13658816.2015.1104316

Dastgerdi AS, Luca GD (2019) Specifying the significance of historic sites in heritage planning. Conserv Sci Cult Herit 18(1):29-39. https://doi.org/10 6092/issn.1973-9494/9225

Dean J, Regier K, Patel A, Wilson K, Ghassemi E (2018) Beyond the cosmopolis: Sustaining hyper-diversity in the suburbs of Peel Region, Ontario. Urban Plan 3(4):38-49. https://doi.org/10.17645/up.v3i4.1700

Elshater A (2019) The predicament of post-displacement amidst historical sites: a design-based correlation between people and place. Herit Soc 12(2-3):85-115. https://doi.org/10.1080/2159032X.2021.1879355

Elshater A, Abusaada H, Afifi S (2019) What makes livable cities of today alike? Revisiting the criterion of singularity through two case studies. Cities Int $J$ Urban Policy Plan 92:273-291. https://doi.org/10.1016/j.cities.2019.04.008

Fu X, Zhang W, Lehto XY, Miao L (2017) Celebration of heritage: linkages between historical re-enactment festival attributes and attendees' value perception. J Travel Tour Mark 35(2):202-217. https://doi.org/10.1080/ 10548408.2017.1350618

Hadfield P (2015) The night-time city. Four modes of exclusion: reflections on the urban studies special collection. Urban Stud 52(3):606-616. https:// doi.org/10.1177/0042098014552934

Hassan AM, Lee H, Yoo U (2016) From medieval Cairo to modern Masdar City: lessons learned through a comparative study. Archit Sci Rev 59(1):1-14. https://doi.org/10.1080/00038628.2015.1015947

Kalinauskaite I, Haans A, Kort YA, ljsselsteijn WA (2018) Atmosphere in an urban nightlife setting: a case study of the relationship between the sociophysical context and aggressive behavior. Scand J Psychol 59(2):223-235. https://doi.org/10.1111/sjop.12431

Kohon J (2018) Social inclusion in the sustainable neighborhood? Idealism of urban social sustainability theory complicated by realities of community planning practice. City Cult Soc 15:14-22. https://doi.org/10.1016/j.ccs. 2018.08.005

Kraftl P, Bolt G, Van Kempen R (2019) Hyper-diversity in/and geographies of childhood and youth. Soc Cult Geogr 20(9):1 189-1197. https://doi.org/ $10.1080 / 14649365.2018 .1491619$
McClinchey KA (2017) Social sustainability and a sense of place: Harnessing the emotional and sensuous experiences of urban multicultural leisure festivals. Leisure/loisir 41(3):391-421. https://doi.org/10.1080/14927713. 2017.1366278

Megeirhi HA, Woosnam KM, Ribeiro MA, Ramkissoon H, Denley TJ (2020) Employing a value-belief-norm framework to gauge Carthage residents' intentions to support sustainable cultural heritage tourism. J Sustain Tour 28(9):1351-1370. https://doi.org/10.1080/09669582.2020.1738444

Nguyen NH (2018) Simulating the generative process of urban form: an application using openSim. J Plan Educ Res 40(4):393-404. https://doi.org/10. $1177 / 0739456 \times 18772069$

Nofre J, Sánchez-Fuarros I, Carlos Martins J, Pereira P, Soares I, Malet-Calvo D, Geraldes M, López Díaz A (2017) Exploring nightlife and urban change in Bairro Alto, Lisbon. City Commun 16(3):330-344. https://doi.org/10.1111/ cico. 12248

O'Kane B (2016) The mosques of Egypt. The American University in Cairo Press, Cairo

Peterson M (2016) Living with difference in hyper-diverse areas: how important are encounters in semi-public spaces? Soc Cult Geogr 18(8):10671085. https://doi.org/10.1080/14649365.2016.1210667

Pinkster FM (2016) Narratives of neighbourhood change and loss of belonging in an urban garden village. Soc Cult Geogr 17(7):871-891. https://doi.org/ 10.1080/14649365.2016.1139169

Portella A (2014) Visual pollution: Advertising, signage and environmental quality. Ashgate, Farnham and Burlington VT

Roberts M, Eldridge A (2019) Planning the night-time city. Routledge, London, New York

Russo C (2021) The art of care: Urban oppositional practices and the case of the Guerrilla Grafters. City 25(1-2):7-26. https://doi.org/10.1080/13604 813.2021 .1885912

Sakamoto K, lida A, Yokohari M (2018) Spatial patterns of population turnover in a Japanese Regional City for urban regeneration against population decline: is compact city policy effective? Cities 81:230-241. https://doi. org/10.1016/j.cities.2018.04.012

Seijas A, Gelders MM (2021) Governing the night-time city: the rise of night mayors as a new form of urban governance after dark. Urban Stud 58(2):316-334. https://doi.org/10.1177/0042098019895224

Sharifi A (2019) Resilient urban forms: A macro-scale analysis. Cities 85:1-14. https://doi.org/10.1016/j.cities.2018.11.023

Talebian K, Riza M (2020) Mashhad, city of light. Cities 101:1-14. https://doi. org/10.1016/j.cities.2020.102674

Tasan-Kok T, Kempen RV, Raco M, Bolt G (2014) Towards hyper-diversified European cities: a critical literature review. Utrecht University, Utrecht

van Liempt I, van Aalst I, Schwanen T (2014) Introduction: Geographies of the urban night. Urban Stud 52(3):407-421. https://doi.org/10.1177/00420 98014552933

Yun J (2021) Seoul's nocturnal urbanism: an emergent night-time economy of substitute driving and fast deliveries. Urban Stud. https://doi.org/10. 1177/00420980211005963

Yuval-Davis N (2006) Belonging and the politics of belonging. City 40(3):197214. https://doi.org/10.1080/00313220600769331

\section{Publisher's Note}

Springer Nature remains neutral with regard to jurisdictional claims in published maps and institutional affiliations. 